\title{
Load Characteristics with Current Detection Using an Arduino Based ACS712 Sensor
}

\section{Karakteristik Beban dengan Deteksi Arus Menggunakan Sensor ACS712 Berbasis Arduino}

Nur Ratnawati ${ }^{1}$, Sunardi ${ }^{2}$

${ }^{1}$ Mahasiswa Program Studi Teknik Elektro, Universitas Ahmad Dahlan, Indonesia

${ }^{2}$ Dosen Program Studi Teknik Elektro, Universitas Ahmad Dahlan, Indonesia

\section{INFORMASI ARTIKEL}

\section{Riwayat Artikel:}

Dikirimkan 11 Januari 2020, Direvisi 18 Februari 2020,

Diterima 17 Juli 2020.

\section{Kata Kunci:}

Arus Listrik,

Sensor ACS712,

Arduino Uno,

Analog to Digital,

Digital.

\section{Penulis Korespondensi:}

Nur Ratnawati,

Universitas Ahmad Dahlan,

Yogyakarta, Indonesia

Surel:

nurratnawati6@gmail.com

\begin{abstract}
ABSTRAK
This study discusses tools for digital current monitoring using an Arduinobased ACS712 sensor. The current sensor ACS712 5A uses the principle of hall effect and is a current sensor whose circuit complexity is simple. The purpose of this microcontroller is to read data obtained from the sensor using the Analog to Digital Converter $(A D C)$ feature and then display it in the serial monitor. The ATMEGA328 microcontroller is assisted by a current measuring circuit equipped with a sensor mounted in series against the circuit to be measured in order to measure the current flowing in the circuit. The test results show that the sensor can measure the current value at its peak value with an error value of -0.066 and a standard deviation value of 0.011419. Based on the test results it can be seen that the tool can work well and has a good accuracy rate.

Penelitian ini membahas alat untuk monitoring arus secara digital menggunakan sensor ACS712 berbasis Arduino. Sensor arus ACS712 5A menggunakan prinsip hall effect dan merupakan sensor arus yang kompleksitas rangkaiannya sederhana. Kegunaan mikrokontroler ini adalah untuk membaca data yang diperoleh dari sensor menggunakan fitur Analog to Digital Converter (ADC) kemudian ditampilkan dalam serial monitor. Mikrokontroler ATMEGA328 ini dibantu oleh sebuah rangkaian pengukur arus yang dilengkapi sebuah sensor yang dipasang secara seri terhadap rangkaian yang akan diukur agar dapat mengukur arus yang mengalir pada rangkaian tersebut. Hasil pengujian menunjukkan bahwa sensor dapat mengukur nilai arus pada nilai puncaknya dengan nilai error sebesar -0,066 dan nilai standar deviasi sebesar 0,011419. Berdasarkan hasil pengujian tersebut dapat diketahui bahwa alat dapat bekerja dengan baik dan memiliki tingkut akurasi yang baik.
\end{abstract}

This work is licensed under a Creative Commons Attribution-Share Alike 4.0

\section{Sitasi Dokumen ini:}

N. Ratnawati and Sunardi, "Load Characteristics with Current Detection Using an Arduino Based ACS712 Sensor," Buletin Ilmiah Sarjana Teknik Elektro, vol. 2, no. 2, pp. 83-90, 2020. DOI: 10.12928/biste.v2i2.1522 


\section{PENDAHULUAN}

Monitoring arus sangat dibutuhkan untuk memahami daya yang sedang digunakan dan arus yang mengalir pada rangkaian elektronika. Selain itu pengukuran arus juga penting untuk mengetahui terjadinya arus bocor [1]. Secara konvensional, pengukuran arus di dalam suatu rangkaian listrik menggunakan pencatatan secara manual yang rentan terhadap kelalaian. Oleh karena itu, dibutuhkan pengukuran arus secara digital.

Salah satu sensor arus yang kompleksitas rangkaiannya sederhana yaitu sensor arus ACS712 5A [2]. Sensor ACS712 menggunakan prinsip hall effect [3]. Sensor ini mampu mendeteksi arus dari -5 ampere hingga 5 ampere [4]. Sensor ini membutuhkan mikrokontroler yang berfungsi sebagai pengolah data [5]. Board yang dipilih adalah Arduino uno. Berdasarkan paparan tersebut, dilakukan penelitian deteksi arus menggunakan sensor ACS712 berbasis Arduino. Sebuah konsep untuk mengukur arus dan menampilkan grafik perbedaan arus pada beberapa benda elektronik pada layar serial monitor.

Alat ini merupakan salah satu solusi manajemen energi yang memungkinkan konsumen untuk memperoleh data statistik konsumsi energi listrik secara terperinci. Adanya mikrokontroler ATMEGA328 yaitu Arduino Uno menjadi dasar dari pembuatan tugas akhir ini. Kegunaan mikrokontroler ini adalah untuk membaca beberapa data yang diperoleh dari penelitian kemudian ditampilkan dalam serial monitor.

\section{METODE PENELITIAN}

ADC (Analog To Digital Converter) adalah perangkat elektronika yang berfungsi untuk mengubah sinyal analog (sinyal kontinyu) menjadi sinyal digital [6] [7]. Perangkat ADC (Analog To Digital Converter) dapat berbentuk suatu modul atau rangkaian elektronika maupun suatu chip IC. Sebelum menulis program menggunakan software Arduino, hal yang dilakukan pertama kali adalah membuat diagram alir (flowchart) sebagai panduan penulisan program. Saat hardware dimasukan tegangan dalam hal ini catu daya, mikrokontroler akan memulai proses inisialisasi input maupun output serta variabel yang dibutuhkan. Data yang masuk ke dalam Arduino Uno selanjutnya diolah.

Masukan ke mikro arduino yaitu data sensor [8] [9]. Setelah data berhasil terbaca maka data yang terbaca oleh sensor ACS712 kemudian dikirim ke komputer melalui mikrokontroler arduino uno. Output sensor arus ACS712 5A ini akan kita hubungkan ke PIN ADC 0 pada program Arduino.

\subsection{Desain sistem}

Perancangan sistem dipresentasikan dalam bentuk blok diagram yang akan membantu dalam membuat perancangan karakteristik arus beban menggunakan sensor ACS 712 berbasis Arduino Uno. Diagram blok untuk perancangan pengukuran arus dapat dilihat pada Gambar 1.

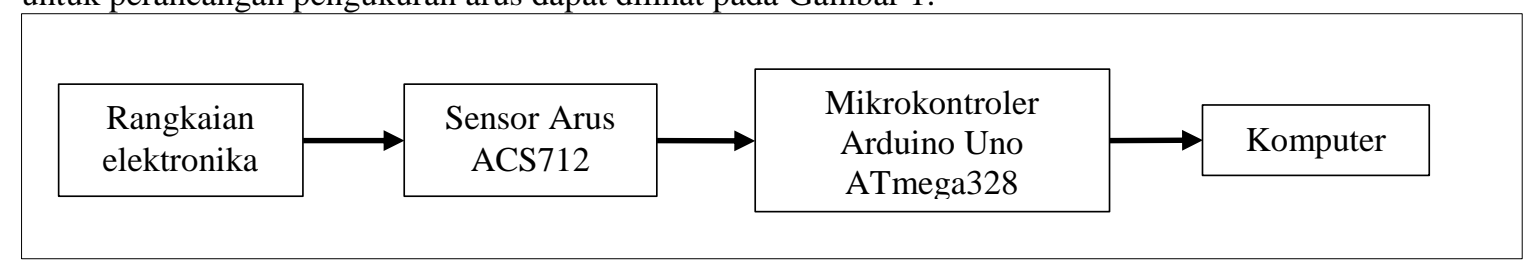

Gambar 1. Diagram Blok Sistem

Dapat diketahui pada Gambar 1, diagram blok sistem pengukuran arus berbasis Mikrokontroler ATmega 328 ini dibutuhkan adanya sebuah rangkaian elektronika. Adanya rangkaian elektronika ini akan diukur nilai arusnya oleh rangkaian pengukur arus yang tersusun dari sensor ACS 712 sehingga akan didapat nilai arus berupa analog. Sedangkan pada Mikrokontroller ATmega328 akan bertujuan untuk mengonversi nilai arus yang berupa analog tersebut menjadi nilai arus berupa digital dengan menggunakan ADC 10 bit sehingga hasil dari pengukuran arus tersebut dapat ditampilkan pada komputer dalam bentuk sinyal arus.

Apabila arus yang diukur mempunyai nilai kecil maka sinyal arus yang akan ditampilkan pada komputer akan mempunyai nilai peak yang rendah pula begitu juga sebaliknya apabila nilai arus yang terukur besar maka nilai peak pada sinyal arus yang ditampilkan juga akan tinggi. Terminal list dan pin out ACS712 ditunjukkan pada Gambar 2. Deskripsi fungsi kaki ACS712 dapat dilihat pada Tabel 1.

Rangkaian alat yang dimaksud adalah, rangkaian keseluruhan alat yang telah di packing dijadikan satu. Dalam rangkaian keseluruhan alat ini terdapat sensor ACS712 yang berfungsi untuk mengukur arus, dan Arduino sebagai board. Juga terdapat dua buah lubang output dan satu buah lubang input. Di dalam wadah tersebut terdapat rangkaian berupa arduino, dan sensor arus. Rangkaian komponen tersebut dapat dilihat pada gambar 3. bentuk rangkaian komponen pada alat penelitian. 


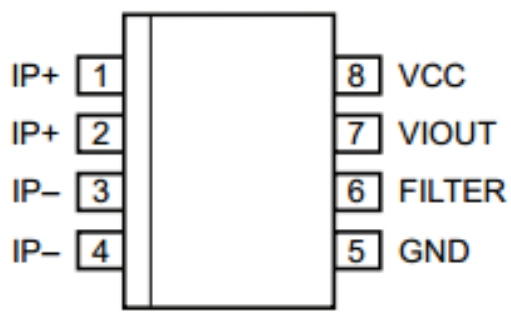

Gambar 2 Pin Out ACS 712

Tabel 1. Fungsi kaki ACS712

\begin{tabular}{|c|c|l|}
\hline No & Nama & \multicolumn{1}{|c|}{ Keterangan } \\
\hline 1,2 & IP + & Masukan Arus \\
\hline 3,4 & IP - & Keluaran Arus \\
\hline 5 & GND & Ground \\
\hline 6 & Filter & Terminal untuk kapasitor di luar, untuk menentukan luas jangkauan \\
\hline 7 & Vout & Keluaran tegangan analog \\
\hline 8 & VCC & Tegangan masukan 5V \\
\hline
\end{tabular}

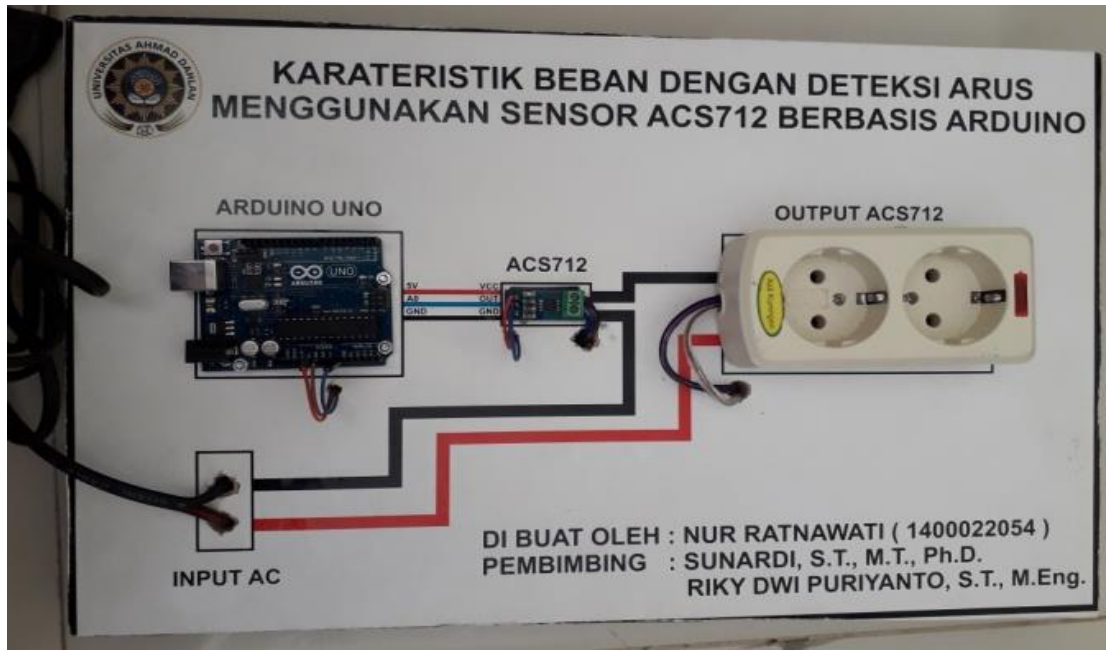

Gambar 3. Bentuk rangkaian komponen pada alat penelitian

\subsection{Algoritme}

Sebelum menulis program menggunakan software Arduino, hal yang dilakukan pertama kali adalah membuat diagram alir (flowchart) sebagai panduan penulisan program. Bentuk flowchartnya dapat dilihat pada Gambar 4. Proses yang terjadi pada flowchart Gambar 4 yaitu alur jalannya program. Output sensor arus ACS712 5A ini akan kita hubungkan ke PIN ADC 0 pada program Arduino. Kemudian langsung kita olah datanya pada program untuk menampilkan arus pada beban.

Pembacaan flowchart pada Gambar 4 adalah ketika beban dinyalakan/ start sensor akan membaca data (nilai arus pada beban). Masukan ke mikro Arduino yaitu data sensor. Setelah data berhasil terbaca maka data yang terbaca oleh sensor ACS712 kemudian dikirim ke komputer melalui mikrokontroler Arduino Uno. Untuk memunculkan hasil pengukuran dengan alat agar tidak jauh berbeda dengan hasil pengukuran pada clampmeter dan perhitungan secara manual dilakukan beberapa kali uji coba program yang diambil dari referensi jurnal.

Listing program pengukuran arus dapat dilihat pada Listring 1. Pada listing program tersebut metode yang digunakan adalah mengambil data sebanyak 1000 data kemudian diambil data yang paling besar. Data yang paling besar ditampilkan pada serial monitor komputer. Persamaan untuk menghitung nilai arus adalah

$$
I=\frac{\operatorname{abs}\left(v_{a d c}-2.5\right)}{0.066}
$$

Dengan

$$
v_{a d c}=\operatorname{data}_{\max }\left(\frac{5}{1023}\right)
$$




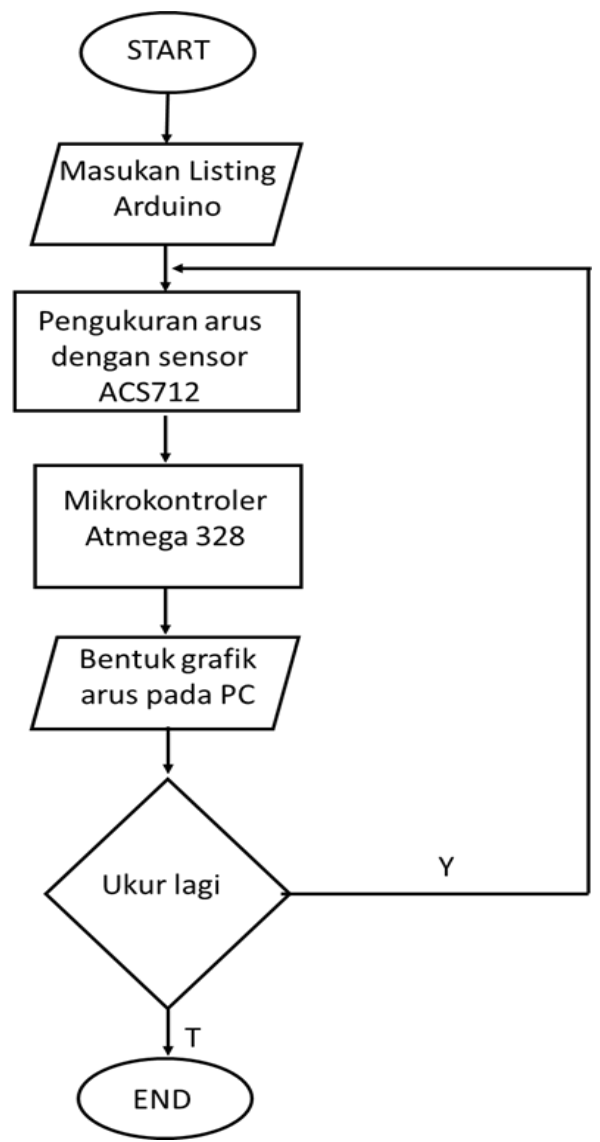

Gambar 4. Diagram Alir

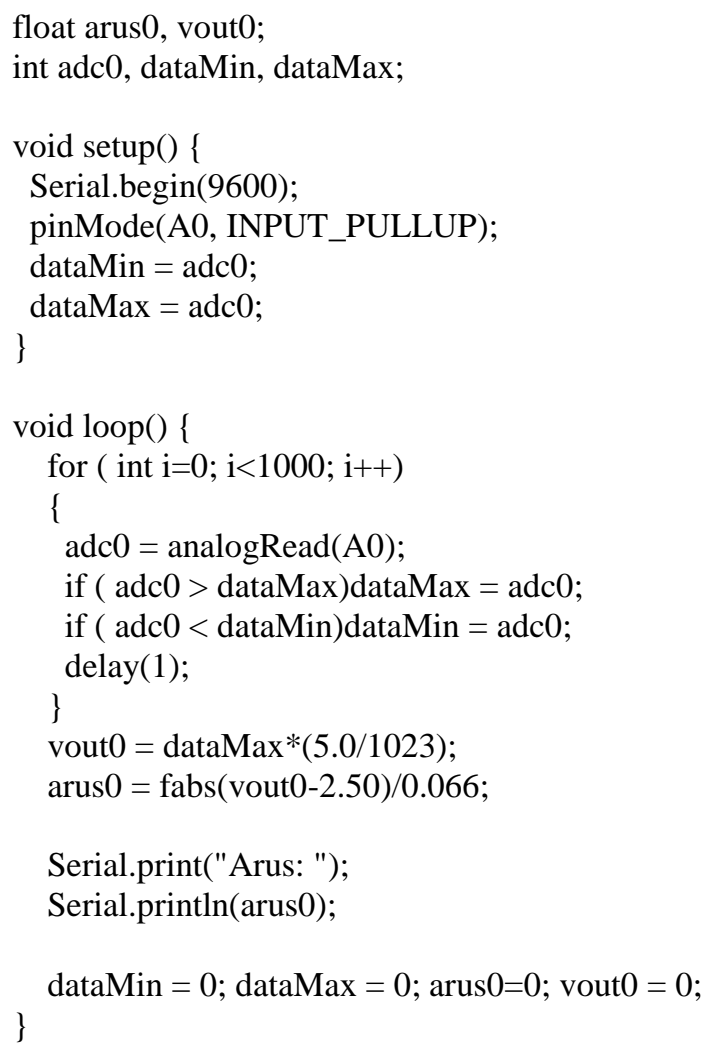

Listing 1. Program Pengukuran Arus 


\section{HASIL DAN PEMBAHASAN}

Setelah dilakukan perancangan software dan hardware langkah selanjutnya yaitu dengan melakukan pengujian data ADC sensor ACS712 untuk mengetahui nilai arus yang diukur. Pertama hubungkan kabel male female arduino ke sensor ACS712 sesuai dengan VCC, Ground dan Vout. Kemudian hubungkan kabel pada alat ke sumber arus AC atau PLN dengan tegangan 220V. Beri beban pada alat tersebut kemudian buka program pengujian data adc pada software Arduino. Dalam pengujian data ini menggunakan clampmeter sebagai pembanding dengan alat yang telah dirancang. Dari pengambilan data menggunakan alat yang telah dirancang dan menggunakan clampmeter dapat diketahui nilai errornya.

\subsection{Hasil Pengujian sensor ACS712}

Pada tahap pengujian sistem ini dilakukan dengan tujuan untuk mengetahui hasil dari perancangan yang telah dibuat pada Bab 3. Pada pengujian terhadap keseluruhan sistem ini berguna untuk mengetahui bagaimana kinerja dan tingkat keberhasilan dari sistem tersebut. Sebelum melakukan pengujian alat secara keseluruhan, terlebih dahulu dapat dilihat kondisi alat yang akan digunakan untuk mengukur arus menggunakan sensor ACS712 berbasis arduino dan pengukuran dengan clampmeter. Rangkaian alat penelitian tersebut memiliki panjang $40 \mathrm{~cm}$ dan lebar $25 \mathrm{~cm}$ yang dirangkai lebih aman agar terhindar dari sengatan listrik.

Pengujian dilakukan selama tiga kali. Masing-masing mengambil 9 sampel kemudian diambil nilai ratarata. Pada pengujian pertama dengan beban lampu 15watt dapat dihitung nilai rata-ratanya 0,060. Untuk pengujian kedua dapat diketahui nilai rata-rata 0,060 dan pada pengujian ketiga nilai rata-ratanya 0,064 . Dengan mengetahui nilai rata-rata dapat diketahui nilai error sebesar 0,$001 ; 0,001 ;-0,003$. Dari pengambilan data tersebut dapat di lihat pada tabel 3.1 pengujian dengan beban lampu 15 watt.

Tabel 2 Dengan beban Lampu 15 Watt

\begin{tabular}{|c|c|c|c|c|}
\hline Beban & Pengujian & Rata-rata & Pengukuran Clampmeter & Error \\
\hline \multirow{3}{*}{ Lampu 15W } & 1 & 0,060 & 0,061 & 0,001 \\
\cline { 2 - 5 } & 2 & 0,060 & 0,061 & 0,001 \\
\cline { 2 - 5 } & 3 & 0,064 & 0,061 & $-0,003$ \\
\hline
\end{tabular}

Pengujia dengan beban charger hp samsung 10watt selama tiga kali. Masing-masing mengambil 9 sampel kemudian diambil nilai rata-rata. Pada pengujian pertama dengan beban charger hp samsung 10watt dapat dihitung nilai rata-ratanya 0,028 . Untuk pengujian kedua dapat diketahui nilai rata-rata 0,028 dan pada pengujian ketiga nilai rata-ratanya 0,02 . Dengan mengetahui nilai rata-rata dapat diketahui nilai error sebesar $-0,008 ;-0,008 ; 0$. Dari pengambilan data tersebut dapat di lihat pada tabel 3.2 pengujian dengan beban charger hp samsung 10watt.

Tabel 3 Pengujian dengan beban charger hp samsung 10watt

\begin{tabular}{|c|c|c|c|c|}
\hline Beban & Pengujian & Rata-rata & Pengukuran Clampmeter & Error \\
\hline \multirow{3}{*}{ Charger hp samsung } & 1 & 0,028 & 0,020 & $-0,008$ \\
\cline { 2 - 5 } & 2 & 0,028 & 0,020 & $-0,008$ \\
\cline { 2 - 5 } & 3 & 0,02 & 0,020 & 0 \\
\hline
\end{tabular}

Pengujian dengan beban lampu 15watt dilakukan selama tiga kali. Masing-masing mengambil 9 sampel kemudian diambil nilai rata-rata. Pada pengujian pertama dengan beban charger hp samsung 10watt dapat dihitung nilai rata-ratanya 0,031 . Untuk pengujian kedua dapat diketahui nilai rata-rata 0,033 dan pada pengujian ketiga nilai rata-ratanya 0,034 . Dengan mengetahui nilai rata-rata dapat diketahui nilai error sebesar $-0,016 ;-0,018 ;-0,019$. Dari pengambilan data tersebut dapat di lihat pada tabel 3.3 pengujian dengan beban charger hp samsung 10watt.

Tabel 4. Pengujian dengan beban lampu 5watt

\begin{tabular}{|c|c|c|c|c|}
\hline Beban & Pengujian & Rata-rata & Pengukuran Clampmeter & Error \\
\hline \multirow{3}{*}{ Lampu 5watt } & 1 & 0,031 & 0,015 & $-0,016$ \\
\cline { 2 - 5 } & 2 & 0,033 & 0,015 & $-0,018$ \\
\cline { 2 - 5 } & 3 & 0,034 & 0,015 & $-0,019$ \\
\hline
\end{tabular}


Pengujian dengan beban charger laptop lenovo 40watt dan lampu 15watt. Masing-Masing mengambil 9 sampel kemudian diambil nilai rata-rata. Pada pengujian pertama dengan beban charger laptop lenovo 40watt dan lampu 15watt dapat dihitung nilai rata-ratanya 0,40. Untuk pengujian kedua dapat diketahui nilai rata-rata 0,32 dan pada pengujian ketiga nilai rata-ratanya 0,35 . Dengan mengetahui nilai rata-rata dapat diketahui nilai error sebesar $-0,11 ;-0,03 ;-0,06$. Dari pengambilan data tersebut dapat di lihat pada tabel 3.4 pengujian dengan beban charger laptop lenovo $40 \mathrm{~W}$ dan lampu $15 \mathrm{~W}$.

Tabel 5. Pengujian dengan beban charger laptop lenovo 40W dan lampu 15W.

\begin{tabular}{|c|c|c|c|c|}
\hline Beban & Pengujian & Rata-rata & Pengukuran Clampmeter & Error \\
\hline \multirow{3}{*}{ charger laptop lenovo 40W dan } & 1 & 0,40 & 0,29 & $-0,11$ \\
\cline { 2 - 5 } & 2 & 0,32 & 0,29 & $-0,03$ \\
\cline { 2 - 6 } & 3 & 0,35 & 0,29 & $-0,06$ \\
\hline
\end{tabular}

Pengujian dengan beban charger laptop lenovo 40watt dilakukan selama tiga kali. Masing-masing mengambil 9 sampel kemudian diambil nilai rata-rata. Pada pengujian dengan beban charger laptop lenovo 40W dapat dihitung nilai rata-ratanya 0,42 . Untuk pengujian kedua dapat diketahui nilai rata-rata 0,42 dan pada pengujian ketiga nilai rata-ratanya 0,42 . Dengan mengetahui nilai rata-rata dapat diketahui nilai error sebesar $-0,24 ;-0,24 ;-0,24$. Dari pengambilan data tersebut dapat di lihat pada tabel 3.5 pengujian dengan beban charger laptop lenovo $40 \mathrm{~W}$.

Tabel 6. Pengujian dengan beban charger laptop lenovo 40W

\begin{tabular}{|c|c|c|c|c|}
\hline \multirow{2}{*}{ Beban } & Pengujian & Rata-rata & Pengukuran Clampmeter & Error \\
\hline \multirow{3}{*}{ charger laptop lenovo 40W } & 1 & 0,42 & 0,18 & $-0,24$ \\
\cline { 2 - 5 } & 2 & 0,42 & 0,18 & $-0,24$ \\
\cline { 2 - 5 } & 3 & 0,42 & 0,18 & $-0,24$ \\
\hline
\end{tabular}

\subsection{Standar Deviasi}

Setelah pengujian mendapatkan data dari percobaan, dapat diketahui nilai standar deviasi yang ditunjukkan pada Tabel 7.

Tabel 7. Nilai standar deviasi

\begin{tabular}{|c|c|c|c|c|c|c|c|}
\hline No & Nama perang-kat & Daya & $\begin{array}{c}\text { Rata-rata } \\
\text { Arus }\end{array}$ & $\begin{array}{l}\text { Clamp- } \\
\text { meter }\end{array}$ & Error & Deviasi & $\begin{array}{c}\text { Deviasi } \\
\text { Kuadrat }\end{array}$ \\
\hline 1 & \multirow{3}{*}{ Lampu bohlam } & \multirow{3}{*}{$15 \mathrm{~W}$} & 0,060 & 0,061 & 0,001 & 0,067 & 0,004489 \\
\hline 2 & & & 0,060 & 0,061 & 0,001 & 0,067 & 0,004489 \\
\hline 3 & & & 0,064 & 0,061 & $-0,003$ & 0,063 & 0,003969 \\
\hline 1 & \multirow{3}{*}{ Charger hp samsung } & \multirow{3}{*}{$10 \mathrm{~W}$} & 0,028 & 0,020 & $-0,008$ & 0,058 & 0,003364 \\
\hline 2 & & & 0,028 & 0,020 & $-0,008$ & 0,058 & 0,003364 \\
\hline 3 & & & 0,02 & 0,020 & 0 & 0,066 & 0,004356 \\
\hline 1 & \multirow{3}{*}{ Lampu bohlam } & \multirow{3}{*}{$5 \mathrm{~W}$} & 0,031 & 0,015 & $-0,016$ & 0,05 & 0,0025 \\
\hline 2 & & & 0,033 & 0,015 & $-0,018$ & 0,048 & 0,002304 \\
\hline 3 & & & 0,034 & 0,015 & $-0,019$ & 0,047 & 0,002209 \\
\hline 1 & \multirow{3}{*}{$\begin{array}{l}\text { charger laptop lenovo } \\
40 \mathrm{~W} \text { dan lampu } 15 \mathrm{~W}\end{array}$} & \multirow{3}{*}{$55 \mathrm{~W}$} & 0,40 & 0,29 & $-0,11$ & $-0,044$ & 0,001936 \\
\hline 2 & & & 0,32 & 0,29 & $-0,03$ & 0,036 & 0,001296 \\
\hline 3 & & & 0,35 & 0,29 & $-0,06$ & 0,006 & 0,000036 \\
\hline 1 & \multirow{3}{*}{ Charger laptop lenovo } & \multirow{3}{*}{$40 \mathrm{~W}$} & 0,42 & 0,18 & $-0,24$ & $-0,174$ & 0,030276 \\
\hline 2 & & & 0,42 & 0,18 & $-0,24$ & $-0,174$ & 0,030276 \\
\hline 3 & & & 0,42 & 0,18 & $-0,24$ & $-0,174$ & 0,030276 \\
\hline & \multicolumn{4}{|l|}{ Error rata-rata } & $-0,066$ & & \\
\hline & \multicolumn{4}{|l|}{ Rata-rata Deviasi } & & & 0,008343 \\
\hline & \multicolumn{4}{|l|}{ Standar Deviasi } & & & 0,011419 \\
\hline
\end{tabular}


Dari hasil Tabel 7 dapat diketahui bahwa standar deviasi untuk percobaan sensor arus ACS712 adalah 0,011419. Sehingga dapat disimpulkan bahwa semakin besar nilai standar deviasi maka akan semakin besar pula variasi rentang datanya. Sedangkan jika nilai standar deviasi semakin kecil maka akan semakin mendekati rata-rata. Jadi standar deviasi yang baik adalah standar deviasi yang sedikit atau rendah. Sedangkan untuk error rata-rata yang diperoleh dari pengujian sensor arus didapat -0,066. Dari hasil error dan error rata-rata dapat diketahui bahwa semakin kecil nilai error yang kita dapat maka semakin bagus sampling data yang diambil.

\subsection{Rangkaian Alat}

Rangkaian alat yang dimaksud adalah rangkaian keseluruhan alat yang telah dijadikan satu. Dalam rangkaian keseluruhan alat ini terdapat sensor ACS712 yang berfungsi untuk mengukur arus, dan Arduino sebagai board. Juga terdapat dua buah lubang output dan satu buah lubang input. Adapun 2 buah lubang output tersebut dapat dilihat pada Gambar 5.

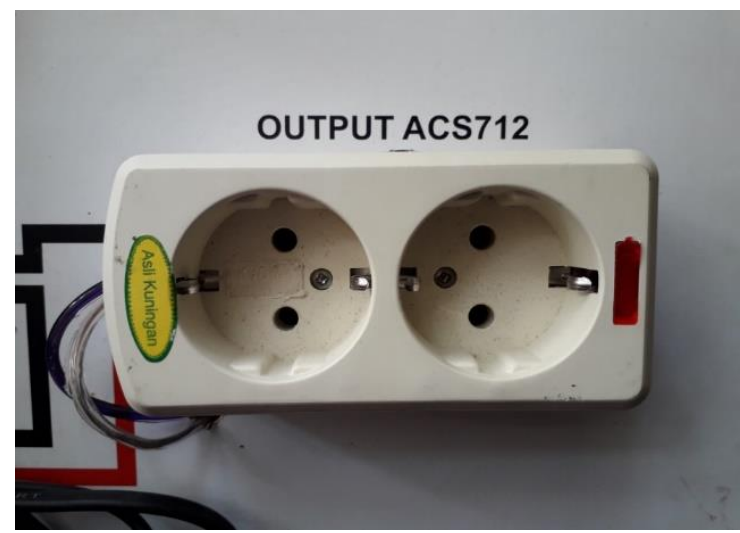

Gambar 5. Dua (2) buah lubang output

Pada gambar 6 tersebut terdapat dua buah lubang yang ada pada wadah rangkaian. Masing-Masing lubang tersebut memiliki fungsi digunakan untuk menyambungkan antara beban dan sensor kemudian nilai dari pengujian sensor akan muncul pada layar laptop. Untuk melakukan pengukuran dengan clampmeter kabel harus dibelah menjadi dua jalur seperti ditunjukkan pada Gambar 6.

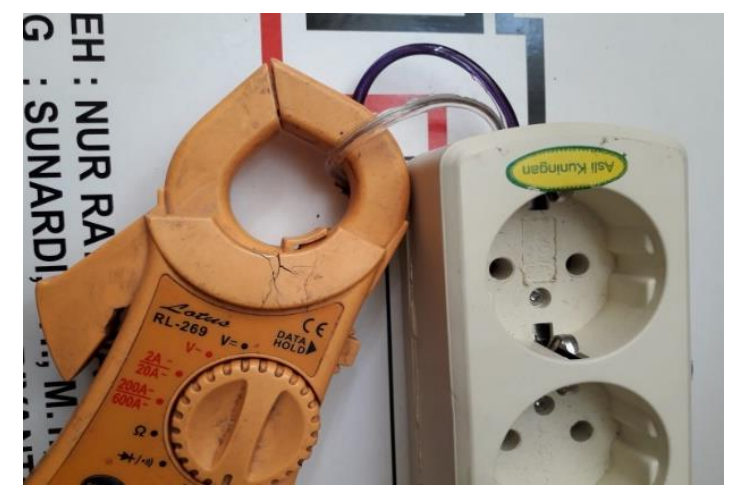

Gambar 6. kabel yang dibelah untuk mengukur arus dengan clampmeter

\section{KESIMPULAN}

Pada hasil yang telah didapatkan dalam semua pengujian. Sensor arus dan papan Arduino dapat bekerja, namun dalam tingkat akurasi sensor arus acs712 masih kurang akurat sehingga dalam pengambilan data perlu dilakukan berkali-kali untuk menentukan nilai yang mendekati error 0. Dengan melakukan perancangan dan pengukuran arus menggunakan sensor ACS712 berbasis Arduino Uno, maka dapat ditarik sebuah kesimpulan, yaitu: Dengan adanya rancangan alat untuk mengukur arus secara digital memudahkan dalam memastikan arus yang mengalir. Pemrograman Arduino harus tepat, sehingga error yang muncul mendekati 0. Standar deviasi dapat diketahui setelah menentukan nilai error-nya. Pengukuran secara digital hasilnya belum tentu akurat. Dari hasil data dapat diketahui nilai standar deviasi 0,011419 bisa dikatakan alat yang dirancang mendekati nilai error 0 . 


\section{UCAPAN TERIMA KASIH}

Dengan ucapan terima kasih skripsi ini kupersembahkan kepada Ibu yang selalu berjuang dan berkorban tenaga, waktu, dan materi untuk mewujudkan impianku. Selalu bersabar menunggu sampai larut malam untuk memastikan aku pulang. Bapak Riky Dwi Puriyanto dan Bapak Alfian Ma'arif selaku dosen pembimbing dalam menyelesaikan tugas akhir ini. Teman-teman seperjuangan, angkatan 2014 Teknik Elektro Fakultas Teknologi Industri, Universitas Ahmad Dahlan. Evrynda, Janu, Sindi, mas Okik, mas Galeh terima kasih atas dukungan dan bantuannya dalam menyelesaikan skripsi ini.

\section{REFERENSI}

[1] Hartono, Sugito, and R. F. Abdullatif, "Sensor Kebocoran Arus Listrik pada Aliran Air Water Heater," Jurnal Teras Fisika, vol. 1, no. 2, pp. 15-18, Sep. 2018.

[2] M. Taif, M. Abbas, M. J.-J. Pro. Vol, and U. 2019, "Penggunaan Sensor ACS712 dan Sensor Tegangan untuk Pengukuran Jatuh Tegangan Tiga Fasa Berbasis Mikrokontroler dan Modul GSM shield," Jurnal Protek, vol. 6, no. 1, pp. 42-47, 2018.

[3] B. G. Melipurbowo, "Pengukuran Daya Listrik Real Time dengan Menggunakan Sensor Arus ACS712," Orbith: Majalah Ilmiah Pengembangan Rekayasa dan Sosial, vol. 12, no. 1, pp. 17-23, Mar. 2016.

[4] T. P. Satya, F. Puspasari, H. Prisyanti, and E. R. Meilani Saragih, "Perancangan dan Analisis Sistem Alat Ukur Listrik Menggunakan Sensor ACS712 Berbasis Arduino Uno dengan Standard Clampmeter," Simetris: Jurnal Teknik Mesin, Elektro dan Ilmu Komputer, vol. 11, no. 1, pp. 39-44, Apr. 2020.

[5] R. Kurniawan, "Perancangan Alat Monitoring Arus pada Circuit Breaker Menggunakan Sensor ACS712 dan Tampilan LCD," INFORMATIKA: Jurnal Informatika, Manajemen dan Komputer, vol. 10, no. 1, pp. 12-17, May 2018.

[6] R. I. Putra, S. Sunardi, and R. D. Puriyanto, "Monitoring Tegangan Baterai Lithium Polymer pada Robot Line Follower Secara Nirkabel," Buletin Ilmiah Sarjana Teknik Elektro, vol. 1, no. 2, p. 73, 2019.

[7] R. D. Listianto, S. Sunardi, and R. D. Puriyanto, "Monitoring Tegangan Baterai Lithium Polymer pada Robot Sepak Bola Beroda secara Nirkabel,” Buletin Ilmiah Sarjana Teknik Elektro, vol. 1, no. 1, p. 1, 2019.

[8] A. Ma'arif, I. Iswanto, A. A. Nuryono, and R. I. Alfian, "Kalman Filter for Noise Reducer on Sensor Readings," Signal and Image Processing Letters, vol. 1, no. 2, pp. 11-22, Jul. 2019.

[9] M. I. Febryansah, A. Yudhana, and A. Ma'arif, "Urinoir Analyzer Pintar Pendeteksi Kelainan Pada Fungsi Ginjal Dengan Analisis Kadar Ph Dan Warna Pada Urin,” Mobile and Forensics, vol. 2, no. 1, pp. 36-44, May 2020.

\section{BIOGRAFI PENULIS}

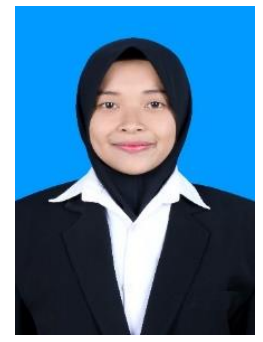

\section{Nur Ratnawati}

Penulis pertama adalah mahasiswi program studi teknik elektro universitas Ahmad Dahlan yang telah menyelesaikan pendidikan sarjana di program studi tersebut.

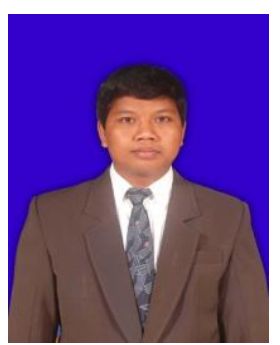

\section{Sunardi}

Penulis kedua adalah dosen program studi Teknik elektro dan magister teknologi informasi, Universitas Ahmad Dahlan. Saat ini, beliau menjabat sebagai dekan fakultas teknologi industri, Universitas Ahmad Dahlan. 